\title{
Street Level Divergence in the Functioning of Social Welfare Networks
}

\author{
J. Travis Bland - University of Illinois at Springfield
}

\begin{abstract}
Much effort has been devoted to the evaluation of network effectiveness. Recent scholarship has made an important distinction between network outcomes or productivity and the underlying dynamics or processes that ultimately shape the nature of such joint actions. This article is interested in the process side of this effectiveness equation and, more specifically, in the possibility of process-related divergence at the street level. What if, due to such divergence, networks are not functioning as expected by participants at the managerial level of networks? What are the potential implications of such a mismatch? And, how might this complicate efforts to assess the process and productivity sides of the network effectiveness equation?
\end{abstract}

Keywords: Street Level Divergence, Networks, Social Welfare

In many instances, the traditional top-down approach of the government has failed to address increasingly complex issues confronting society. These failures have sparked a transformation in the delivery of many public services, such that the network has become the new shape of the public sector (Goldsmith \& Eggers, 2004). As stated by Agranoff and McGuire (2001, p. 319), "[j]ust as the bureaucratic organization was the signature organizational form during the industrial age, the emerging information or knowledge age gives rise to the network, where persons link across internal functions, organization boundaries, and even geographic boundaries." The outcomes or effectiveness of this network approach can vary significantly. Yet, as reported by Vangen and Huxham (2003, p. 6), there is widespread evidence that networks are "difficult to manage and the likelihood of disappointing outputs and failure is high" (for example, see Gould, Ebers, \& Clinchy, 1999; Hora \& Millar, 2012). Confronting these difficulties, policymakers, practitioners, and program evaluators would like to understand the key factors contributing to the variations in network effectiveness.

The network is a discrete approach to governance, where power and control are interorganizationally and, often, inter-jurisdictionally dispersed and decentralized. Here, as defined by Lynn, Heinrich, and Hill (2001, p. 7), the term "governance" refers to the "regimes of laws, rules, judicial decisions, and administrative practices that constrain, prescribe, and enable the provision of publicly supported goods and services." In relation to network effectiveness, then, how can participants in a dispersed and decentralized governance approach be induced to converge on the achievement of a particular objective? What factors might pose as obstacles to such convergence and the solving of what is often referred to as the collective action problem (Ostrom, 1990)? How can these factors be managed to increase the likelihood of network effectiveness?

Much scholarship has been devoted to the questions raised above and to evaluating the effectiveness of the network approach to governance (Emerson \& Nabatchi, 2015; Romzek, LeRoux, J ohnston, Kempf, \& Piatak, 2014; Thomson \& Perry, 2006; Thomson, Perry, \& Miller, 2009; Turrini, Cristofoli, \& Frosini, 2010). These studies make an important distinction between network outcomes or productivity and the underlying dynamics or processes that ultimately shape the nature of the joint actions taken by network participants. Each is important to network effectiveness. The processes in and of themselves matter, but they are tied to and integral to the realization of desired outcomes. Yet, as asserted by Emerson and Nabatchi 
J ournal of Public and Nonprofit Affairs

(2015), the study of network effectiveness requires the separation, and better articulation and specification, of the factors related to the process and productivity sides of the effectiveness equation. This article is interested in the process-related factors, which are so vital to the longterm sustainability and maintenance of networks (Turrini et al., 2010).

Scholars have already given considerable attention to the assessment of process-related factors, such as trust, reciprocity, other forms of social capital, and key structural or administrative considerations. These studies, however, do not give adequate attention to the three distinct levels of governance: the institutional, the managerial, and the technical or street levels (Lynn et al., 2001). Neglecting an important piece of the overall governance puzzle, the potential for process-related divergence at the street level is not given due consideration (Considine \& Lewis, 1999, 2012; Maroulis \& Wilensky, 2014). Since power and control are dispersed and decentralized in the network approach, participants at the street level may occupy the highest leverage point when it comes to process-related factors. Divergence, then, could alter the nature of the joint actions taken, otherwise referred to as network functioning, and complicate evaluations of network effectiveness.

Offering an exploratory analysis of the functioning of 13 social welfare networks in Virginia, this article demonstrates the possibility of process-related divergence at the street level. Then, this article gives full consideration to the implications of such divergence and, drawing from the networks where divergence was minimal, discusses how it might be avoided. Before offering the analysis, this article provides some conceptual clarity on the process side of the effectiveness equation and introduces the concept of network functioning.

\section{The Process Side of Network Effectiveness}

As a discrete approach or form of governance, a general systems view illuminates the process side of the network effectiveness equation. Networks are systems, embedded in environments, and have their own inputs (participants and their organizations), throughput processes, and outputs and outcomes. Thomson and Perry (2006) describe the throughput processes as a "black box" because they are the least understood. Yet, it is this component that enables or makes it possible for the inputs to operate as a collective and take joint actions. Provan and Kenis (2007) argued that the network was not an undifferentiated form. To capture the potential variability in the nature of those joint actions, then, they introduced the concept of network functioning. They suggested that this variability reflected important differences in the throughput processes, including how networks are governed and the level of integration among participants. The overarching assumption was that certain variations will likely serve some purposes or objectives better than other variations.

Provan and Kenis were especially interested in how networks are governed, including whether the responsibilities are brokered or shared and whether they are participant governed or externally governed. Many other scholars, however, have emphasized the potential variability in the levels of integration among participants and how those differences relate to the objectives of the relationship (Bailey \& Koney, 2000; Gajda, 2004; Mandell \& Steelman, 2003; Vangen \& Huxham, 2003). For example, Woodland and Hutton (2012) argue that more complex and higher stakes purposes tend to warrant higher levels of integration. This article argues that the many explanations of the variability in the levels of integration seem most relevant to the throughput processes and best capture the potential variations in the nature of the joint actions taken or network functioning. 
Figure 1. The Relational and Systemic Dimensions of Network Functioning

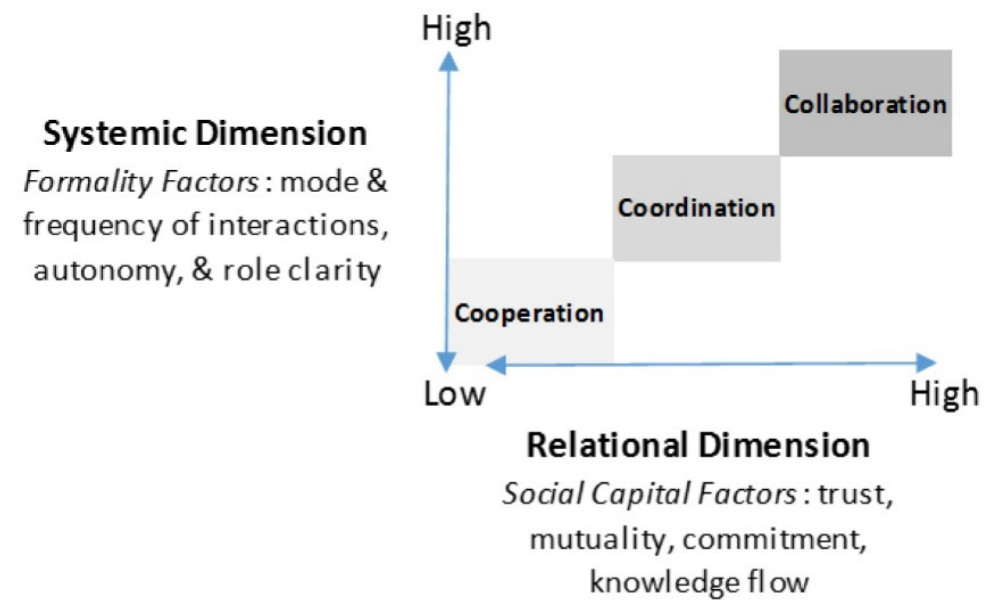

Mattessich, Murray-Close, and Monsey (2001) offer a three-point continuum to help explain the variability in the levels of integration, which this article uses as descriptors of the potential variations in network functioning. On one end of the continuum is cooperation, which is where participants and their organizations relate informally, their resources remain separate, and their interactions take place on an as-needed basis. On the other end of the continuum is collaboration, which is where participants and their organizations relinquish much of their autonomy, pool their resources, and share risk, while pursuing a common and newly created mission. In the middle of this continuum is coordination, which is where participants and their organizations share compatible goals, maintain much of their autonomy, and interact around a specific task of definable length.

Assuming that certain variations in network functioning do serve some objectives better than others, participants will come together to make choices and work out agreements as to the intended variation or level of integration among participants. Emerson, Nabatchi, and Balogh (2012) call this principled engagement, which is the beginning of the throughput processes. This is where, through discovery, definition, deliberation, and determination, network participants develop a shared sense of purpose and a shared theory of action for achieving that purpose. In a mandated or top-down network, which is created by policy dictate or in response to funding requirements (Kenis \& Provan, 2009), principled engagement is similar to the activation and framing stages in network formation, as outlined by Agranoff and McGuire (2001), and carried out primarily by participants in leadership or managerial roles. There are several processrelated factors, then, that must be managed or balanced to help ensure that a shared theory of action (intended variation in network functioning) is actually the theory in use at the street level (Emerson \& Nabatchi, 2015; Romzek et al., 2014; Thomson \& Perry, 2006). Before considering the potential for process-related divergence at the street level, the next subsection outlines the key process-related factors.

\section{Process-Related Factors}

The throughput processes begin with principled engagement and the choice of a variation in network functioning (cooperation, coordination, collaboration), which will best serve the objectives of the relationship. Based on a synthesis of the literature on the varying levels of integration, as referenced above, with Emerson et al.'s (2011), Ansell and Gash's (2008), and 
J ournal of Public and Nonprofit Affairs

Thomson and Perry's (2006) writings on the throughput processes, this article groups the underlying process-related factors into two broad dimensions: the relational and systemic dimensions. As depicted in figure 1 and described below, the operationalization of each dimension as a separate continuum, will serve as the foundation for assessing the potential for process-related divergence at the street level.

\section{Relational Dimension}

The relational dimension includes four process-related factors that together reinforce or produce differing amounts of social capital: trust, internal legitimacy or mutuality, commitment, and knowledge flows. Collaboration as a variation of network functioning is relationally interpersonal and will require much higher amounts of social capital than cooperation, which is relationally impersonal. As with other forms of capital, social capital takes time to develop and requires targeted investments (Thomson, 2001). Investments that target these process-related factors, as reviewed below, will ultimately produce differing amounts of social capital. Higher levels of each factor should serve as a sound indication of higher amounts of social capital, which will ultimately determine how a network functions relationally.

Trust is the common belief among participants that they are dependable and will make a goodfaith effort on behalf of the endeavor. Trust reduces transaction costs. Trust lends itself to a norm of reciprocity, which is when there is high respect for other participants and a sense of obligation that guides exchanges (Coleman, 1988). In situations where trust is low, participant exchanges are more contingent and will be guided by an "I will if you will" mentality (Thomson \& Perry, 2006). Internal legitimacy or mutuality is similar to the notion of fit (Bright, 2013) and is the degree to which participants see their interests as compatible and share an overarching purpose. Commitment is the extent to which participants value the opportunity to participate in the endeavor and will go to great lengths to ensure its success (Porter, Steers, Mowday, \& Boulian, 1974). Last, knowledge flows are a reflection of how freely participants share information, value the opportunity to learn from others, and whether or not these efforts actually serve as a basis for action (Coleman, 1988).

\section{Systemic Dimension}

The systemic dimension includes three process-related factors that together reinforce or shape the infrastructure or procedural arrangements that underlie a network's functioning: mode and frequency of interactions, degrees of autonomy, and role clarity. Here, the focus is on the formality of the linkages among participants. Collaboration as a variation of network functioning is often an outgrowth of felt interdependencies and includes a higher degree of risk to participants (Keast, Mandell, Brown, \& Woolcock, 2004). For this reason, the linkages in a collaboration will require more formality than in a cooperation. When assessed on the three process-related factors described below, higher levels should serve as a sound indication of increased formality, which will ultimately determine how a network functions systemically.

The mode and frequency of interactions refer to type and regularity of participant interactions. Face-to-face and frequent interactions suggest there is a more formalized means of maintaining the links among participants (Woodland \& Hutton, 2012). Degrees of autonomy refer to the amount of control maintained by participants and their home organizations. Formalized linkages often require the relinquishment of some autonomy and include decision-making processes requiring that major decisions be made collectively, not individually (Mandell \& Steelman, 2003). Last, role clarity refers to the assignment of network-specific roles and clarified expectations, which indicates a higher level of formality. 


\section{Potential for Process-Related Divergence}

The distinction between managerial and street levels of governance deserves careful consideration when assessing the process side of the effectiveness equation. Because power and control are dispersed and decentralized in the network approach, street-level participants often wield a great deal of power and discretion in carrying out their work (Lipsky, 1980; Oberfield, 2010). In contrast with the single agency approach to governance, managerial participants are quite limited in their capacity to oversee or control what happens at the street level. When it comes to the process-related factors that underlie and shape the functioning of networks, then, the street-level worker occupies a high leverage point as the day-to-day linking mechanism among participating organizations.

As street-level participants make sense of their roles and responsibilities within a network, they also are making some determinations as to the value of the relationships (Ellis, Davis, \& Rummery, 1999; J ewell \& Glaser, 2006; Rice \& Mitchell, 1973). In other words, do they feel the benefits of participation outweigh the costs? A number of things may influence this sensemaking process, including, for example, the prior experiences working together, the time commitment, the information available, and the complexity of the problem (Chen, 2010; Gofen, 2013; Mandell \& Steelman, 2003; Meek, De Ladurantey, \& Newell, 2007). Depending on how this sense-making process unfolds, the attitudes and perceptions of street-level workers may influence or shape how they approach network participation. What if the social capital among street-level participants is too low and the linkages are not formalized at the level necessary for the network to function as expected by managerial participants? What are the potential implications of such a mismatch in the theory of action, as developed by participants at the managerial level, and the theory in use by participants at the street level? What if the intended variation in network functioning is collaboration, but it is actually functioning as cooperation?

Investigating the potential for process-related divergence at the street level of the network approach to governance, the above questions will guide this article's exploratory analysis of the functioning of 13 social welfare networks in Virginia. Underlying the potential variability in the functioning of these networks (cooperation, coordination, or collaboration) are several processrelated factors that may ultimately determine or shape their functioning. This article groups the like factors into two broad dimensions to be assessed at the street level, as a reflection of the theory in use. Then, this is compared with the theory of action or expectations of participants at the managerial level as to the variation in network functioning that best serves the objectives of their network. Several other questions are considered as well. How might process-related divergence at the street level complicate evaluations of network effectiveness? And, how can such divergence be avoided?

\section{Thirteen Social Welfare Networks in Virginia}

Virginia uses some of if its federal welfare funding to award the Employment Advancement for TANF Participants grant (Virginia Department of Social Services, 2011). This grant awarded funds to welfare-to-work programs that adopted what the request for proposals referred to as "proven service approaches," including, among other things, community partnerships and interagency collaborations. In response to these funding incentives and requirements, many organizations occupying a portion of the social welfare policy space in Virginia explored the potential benefit of linking together and adopting a network approach. This exploration, previously referred to as principled engagement, was carried out primarily by those occupying leadership or managerial roles in these organizations. The grant applications, then, effectively 
served as a formal expression of the shared sense of purpose that developed among organizations and a corresponding theory of action for the associated network.

Facing area-specific challenges and barriers to employment, some networks formed to address transportation, education, and childcare issues, while others dealt with substance abuse and mental health problems. Along with these important differences in the objectives or purposes of these networks, which help define the key factors in the productivity side of the effectiveness equation, their theory of action and underlying process-related expectations, as expressed in the grant proposals, were somewhat vague. Some, however, did express different expectations as to the role of the street-level participants. For example, some expected them to interact and jointly create a plan for addressing client barriers to employment, while others expected them to serve as a referral hub among service providers. In regards to a theory of action, these differences do indicate some expectations as to the level of integration (variation of network functioning) that would be necessary among participants. However, their vagueness also demonstrates that, overall, the process-side of the effectiveness equation may not have been given adequate attention in many of these networks.

These networks, then, were an ideal setting for exploring the potential for process-related divergence at the street levels of this approach to governance. Primarily, the lack of attention given to this issue meant that this was an opportunity for many of the managerial actors to clearly articulate their theory of action for the first time. And, then, to explore whether or not this variation in network functioning was actually the theory in use at the street level.

\section{Sample and Data Collection}

Of the 42 grant-funded social welfare networks in Virginia, this study targeted the 17 that included local departments of social service, which housed the population of interest: the Virginia Initiative for Employment Not Welfare (VIEW) caseworkers. As prime examples of street-level participants (Lipsky, 1980), the VIEW caseworkers all held the same job description, had some control over the distribution of resources, and interacted directly with the welfare clients and many other network participants. They seemed to occupy the highest leverage point, as they were ultimately responsible for client outcomes and had the most comprehensive view of what was taking place at the street level. Thirteen of the 17 programs agreed to participate in this study, providing a study population of 99 VIEW caseworkers and the corresponding 13 grant coordinators. Given the nature of these networks, the grant coordinators could provide an accurate representation of the theory of action developed by participants at the managerial level.

In addition to reviewing the grant applications and surveying and interviewing each grant coordinator to capture the theory of action for each network, this study also surveyed the VIEW caseworkers to capture the theory in use at the street level. The grant coordinators participated at $100 \%$, while 72 VIEW caseworkers completed a survey for a response rate of $72 \%$.

\section{Measurements of Study Constructs at the Street Level}

As depicted in figure 2, this study modeled network functioning as a higher-level formative construct comprised of two second-order formative constructs. The relational dimension, as a second-order constructs, consisted of four first-order reflective constructs. To create the initial pool of items for the relational dimension (Mattessich et al., 2001) measurements of trust (Austin, 2000; Harbert, Finnegan, \& Tyler, 1997), internal legitimacy or mutuality (Margerum, 
Figure 2. Measurement Model

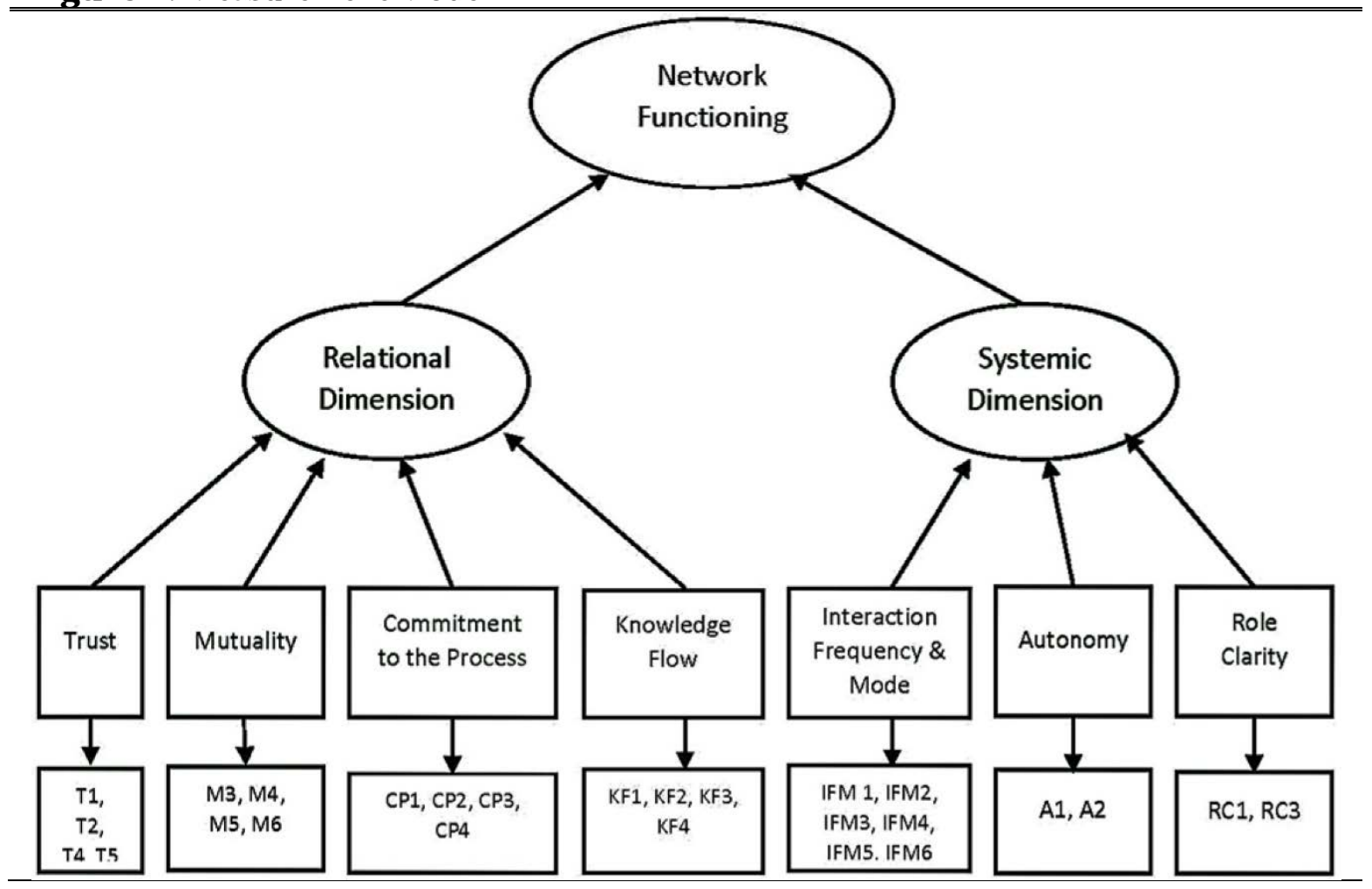

2002), commitment to the process (Margerum, 2001, 2002; Porter et al., 1974), and knowledge flows (Coleman, 1988) were reviewed. The systemic dimension, as a second-order construct, consisted of three first-order reflective constructs. To create the initial pool of items for the systemic dimension (Mandell \& Steelman, 2003; Mattessich et al., 2001) measurements of interaction frequency and mode (Agranoff \& Lindsay, 1983), degrees of autonomy (Gajda, 2004; Margerum, 2002; Taylor-Powell, Rossing, \& Geran, 1998), and role clarity (House \& Rizzo, 1972) were reviewed.

Based on these reviews, measurement items, including mostly four-point Likert scale statements, tailored to the social welfare context, were developed for each of these first-order reflective constructs. The items were included in a draft of the VIEW caseworker survey, which was piloted to obtain feedback on the wording of the statements and to ensure that they were understood in a consistent way. Several suggestions, then, were incorporated into the final survey, which was part of a larger study (see table 1 for this study's measurement items or statements). Several of the statements were negatively phrased and reverse scored to reduce response bias, as indicated by " $\mathrm{r}$ " in table 1 . The respondents were asked to respond based on their perception of the process-related conditions or factors at the street level. After collecting the data, the measurement model was tested in SmartPLS using techniques recommended by Diamantopoulos and Siguaw (2006) and Hair, Hult, Ringle, and Sarstedt (2016). The first step was for first-order reflective construct examination, and step two was for the formative second and higher-order constructs.

First-Order Constructs

Table 2 presents the overall quality of the reflective measures. Cronbach's alpha and composite reliability were calculated to test the reliability of the data. In this stage, TR3, M1, M2, and RC2 
J ournal of Public and Nonprofit Affairs

Table 1 Street-Level Survey Instrument

$$
\text { Relational Dimension (Social Capital) }
$$

T1 (r) When it comes to sharing my knowledge, I am concerned about the possibility of other program staff free-riding.

T2 (r) When I share my knowledge, it reduces the incentives for other program staff to do the work themselves.

T3 When interacting with other program staff, I view them as my colleagues, not as my adversaries.

T4 (r) When interacting with other program staff, there is little personal benefit to communicating openly with them.

T5 (r) When interacting with other program staff, I sometimes feel threatened by those who disagree with me.

M1 What my local department of social services wants to accomplish through this program seems to be the same as the other participating organizations.

M2 (r) Program staff do not share an overarching mission.

M3 This program is guided by a joint mission statement.

M4 Other program staff seem committed to reaching a new and improved understanding of the issues we face.

M5 (r) Other program staff seem unwilling to compromise their positions on many issues.

M6 The interactions of other program staff are reflective of a joint responsibility for the future.

CP1 I am willing to put in a great deal of effort, beyond what is normally expected, in order to help this program be successful.

CP2 This program inspires the very best in me.

CP3 I personally feel some responsibility for the fate of this program.

CP4 Most of the other program staff are willing to do whatever it takes to ensure the success of this program.

KF1 My interactions with other program staff influence future program activities.

KF2 Overall, this program values the opportunity to engage different perspectives.

KF3 A better understanding of the problems and challenges associated with unemployment have resulted from sharing knowledge with other program staff.

KF4 I can learn a great deal from interacting with other program staff.

$$
\text { Systemic Dimension (Formality) }
$$

IMF1 How often do all of the participating organizations meet face-to-face?

IMF2 How often you interact with other VIEW caseworkers concerning this program?

IMF3 How often do you interact with non-VIEW participants?

IMF4 How often are you given the opportunity to share your daily challenges with other program participants?

IMF5 How often do you engage in brainstorming activities with other program participants?

IMF6 Most of my communications with other program staff are face-to-face.

A1 Participation in this program requires the staff and their organizations to relinquish some of their control and authority.

A2 Decisions regarding program activities typically require the support of all participating organizations.

RC1 The relationships among participating organizations in this program are relatively formal (contractual).

RC2 When meeting with the other program staff formal titles or positions are rarely part of the discussion.

RC3 The assigned roles and responsibilities within this program are flexible enough to allow program staff to do what is necessary to ensure success. 
Table 2. First-Order Construct (Reflective) Reliability

\begin{tabular}{lccc}
\hline \hline & AVE & $\begin{array}{c}\text { Composite } \\
\text { Reliability }\end{array}$ & $\begin{array}{c}\text { Cronbach's } \\
\text { Alpha }\end{array}$ \\
\hline Relational Dimension & & & \\
\hline Trust & .555 & .831 & .744 \\
Mutuality & .531 & .819 & .703 \\
Commitment to Process & .572 & .842 & .754 \\
Knowledge Flow & .553 & .831 & .727 \\
Systemic Dimension & & & \\
\hline Interaction Mode \& Frequency & .570 & .887 & .845 \\
Autonomy & .652 & .786 & .503 \\
Role Clarity & .723 & .839 & .624 \\
\hline
\end{tabular}

Table 3. First-Order (Reflective) Construct Factor Loadings

\begin{tabular}{lccccccc}
\hline \hline & Autonomy & Commitment & $\begin{array}{c}\text { Role } \\
\text { Clarity }\end{array}$ & $\begin{array}{c}\text { Knowledge } \\
\text { Flow }\end{array}$ & $\begin{array}{c}\text { Interaction } \\
\text { Mode \& } \\
\text { Frequency }\end{array}$ & Mutuality & Trust \\
\hline A1 & 0.674 & 0.060 & -0.117 & 0.013 & 0.161 & 0.048 & -0.170 \\
A2 & 0.922 & 0.340 & 0.139 & 0.281 & 0.244 & 0.339 & 0.046 \\
CP1 & 0.171 & 0.742 & -0.004 & 0.341 & 0.263 & 0.238 & 0.204 \\
CP2 & 0.356 & 0.752 & 0.396 & 0.658 & 0.324 & 0.471 & 0.210 \\
CP3 & 0.126 & 0.740 & 0.154 & 0.271 & 0.319 & 0.381 & 0.170 \\
CP4 & 0.190 & 0.789 & 0.148 & 0.436 & 0.293 & 0.517 & 0.241 \\
RC1 & 0.001 & 0.067 & 0.803 & 0.218 & 0.266 & 0.011 & 0.114 \\
RC3 & 0.090 & 0.326 & 0.895 & 0.524 & 0.374 & 0.263 & 0.088 \\
KF1 & 0.278 & 0.381 & 0.470 & 0.678 & 0.444 & 0.369 & -0.088 \\
KF2 & 0.171 & 0.317 & 0.501 & 0.735 & 0.297 & 0.455 & 0.207 \\
KF3 & 0.185 & 0.546 & 0.287 & 0.858 & 0.322 & 0.486 & 0.224 \\
KF4 & 0.058 & 0.481 & 0.158 & 0.690 & 0.050 & 0.384 & 0.406 \\
IMF1 & 0.131 & 0.308 & 0.266 & 0.322 & 0.781 & -0.024 & -0.188 \\
IMF2 & 0.137 & 0.345 & 0.213 & 0.105 & 0.806 & -0.072 & -0.232 \\
IMF3 & 0.264 & 0.234 & 0.185 & 0.199 & 0.617 & 0.173 & -0.025 \\
IMF4 & 0.139 & 0.289 & 0.299 & 0.250 & 0.808 & 0.089 & -0.102 \\
IMF5 & 0.241 & 0.281 & 0.317 & 0.396 & 0.823 & 0.184 & -0.088 \\
IMF6 & 0.268 & 0.343 & 0.444 & 0.361 & 0.669 & 0.085 & -0.134 \\
M3 & 0.216 & 0.431 & 0.045 & 0.464 & 0.134 & 0.670 & 0.225 \\
M4 & 0.255 & 0.370 & 0.113 & 0.444 & -0.045 & 0.815 & 0.326 \\
M5 & -0.029 & 0.237 & 0.165 & 0.394 & 0.022 & 0.698 & 0.511 \\
M6 & 0.361 & 0.541 & 0.205 & 0.365 & 0.161 & 0.725 & 0.296 \\
TR1 & -0.100 & 0.114 & 0.068 & 0.113 & -0.270 & 0.190 & 0.752 \\
TR2 & -0.093 & 0.209 & -0.023 & 0.027 & -0.197 & 0.214 & 0.583 \\
TR4 & 0.144 & 0.277 & 0.154 & 0.381 & -0.085 & 0.501 & 0.842 \\
TR5 & -0.189 & 0.180 & 0.080 & 0.122 & -0.055 & 0.338 & 0.778 \\
\hline
\end{tabular}

were the only indicators removed from the initial pool. The remaining items included factor loadings above the 0.5 threshold, and the corresponding reflective constructs met the other reliability criteria, although the relatively low Cronbach's alpha scores suggest that the measures could be improved in future studies. ${ }^{1}$ Convergent validity of the reflective constructs was tested by examining the average variance extracted (AVE). As reported in table 2, all constructs met

\footnotetext{
${ }^{1}$ Autonomy and role clarity do not meet the Cronbach's alpha threshold. However, given that they only include two items, alpha scores tend to be quite low. These reflective constructs do display inter-item correlations in the optimal range of 0.2-0.4 (Briggs \& Cheek, 1986) and meet all other reliability criteria.
} 
J ournal of Public and Nonprofit Affairs

Table 4. Second and Higher-Order Formative

Indicator Multi-Collinearity Test

\begin{tabular}{lc}
\hline \hline & VIF \\
\hline Second-Order: Relational Dimension & \\
Trust & 1.271 \\
Mutuality & 1.907 \\
Commitment to Process & 1.704 \\
Knowledge Flow & 1.771 \\
\hline Systemic Dimension & \\
Interaction Mode \& Frequency & 1.253 \\
Autonomy & 1.073 \\
Role Clarity & 1.174 \\
\hline Higher-Order: Network Functioning & \\
Relational Dimension & 1.168 \\
Systemic Dimension & 1.168 \\
\hline
\end{tabular}

the threshold of 0.5, thus providing evidence that convergent validity was achieved. Discriminant validity also was tested using the Fornell-Larcker criterion and the examination of cross loadings (see table 3). In all cases, each of the item's loadings was higher on its own construct than its cross loadings with other constructs. Discriminant validity was also tested using the heterotrait-monotrait ratio of correlations (HTMT) test, as suggested by Henseler, Ringle, and Sartedt (2015). In all cases, the HTMT value was well below 0.90, establishing discriminant validity between the reflective constructs.

Second- and Higher-Order Constructs

The second- and higher-order formative constructs were evaluated first for multicollinearity. Multicollinearity tests, as reported in table 4, showed that each indicator's variance inflation factor (VIF) value was far less that than the cut-off value of 5. Following the recommendations of Bollen (2014), all formative indicators in this measurement model were retained because they were not highly correlated in the model. This serves as evidence of discriminant validity in that the associated indicators did not belong to the other constructs.

Also reported in table 5, an assessment of the indicator validity for the second- and higher-order constructs was performed using the PLS algorithm method with a bootstrapping of 500 samples. Each path coefficient and associated t-value was calculated, and each was found to be significant. Unfortunately, there was no global measure of network functioning to correlate with each second-order formative construct and establish convergent validity.

In support of content or construct validity, the constructs and measurements are all drawn from or shaped by existing theory. Although there is room for improving several of the measurement items based on the above tests, this study is confident moving forward with this instrument and model as an assessment of the process-related factors that actually shape or determine the variation of network functioning that is in use at the street level. To score each respondent, the weighting for each item was adjusted so that they were treated equally. Then, the associated responses for each dimension were summed, and, for ease of presentation, the scores were transformed so that the scores were out of 100. 
Table 5. Formative Indicator Validity

\begin{tabular}{|c|c|c|c|c|c|}
\hline & $\begin{array}{l}\text { Original } \\
\text { Sample } \\
\text { (O) }\end{array}$ & $\begin{array}{c}\text { Sample } \\
\text { Mean } \\
\text { (M) }\end{array}$ & $\begin{array}{l}\text { Standard } \\
\text { Deviation } \\
\text { (STDEV) }\end{array}$ & $\begin{array}{c}\text { t-Statistic } \\
(|\mathrm{O} / \mathrm{STDEV}|)\end{array}$ & p-Value \\
\hline \multicolumn{6}{|l|}{ Second-Order Formative Constructs } \\
\hline Trust - > Relational Dimension & 0.168 & 0.169 & 0.070 & 2.398 & 0.017 \\
\hline Mutuality - > Relational Dimension & 0.337 & 0.328 & 0.042 & 7.968 & 0.000 \\
\hline Commitment to the Process -> Relational Dimension & 0.375 & 0.369 & 0.057 & 6.611 & 0.000 \\
\hline Info \& Knowledge Flow - > Relational Dimension & 0.380 & 0.373 & 0.050 & 7.635 & 0.000 \\
\hline Interaction Mode \& Frequency - > Systemic Dimension & 0.838 & 0.825 & 0.048 & 17.392 & 0.000 \\
\hline Autonomy -> Systemic Dimension & 0.146 & 0.149 & 0.057 & 2.548 & 0.011 \\
\hline Role Clarity- > Systemic Dimension & 0.237 & 0.232 & 0.048 & 4.992 & 0.000 \\
\hline \multicolumn{6}{|l|}{ Higher-Order Formative Construct } \\
\hline Relational Dimension -> Network Functioning & 0.730 & 0.721 & 0.109 & 6.673 & 0.000 \\
\hline Systemic Dimension -> Network Functioning & 0.459 & 0.447 & 0.120 & 3.837 & 0.000 \\
\hline
\end{tabular}


Table 6. Managerial-Level Survey Instrument

\begin{tabular}{|c|c|}
\hline \multicolumn{2}{|r|}{ Relational Dimension (Social Capital) } \\
\hline T1 & Participating organizations trust one another. \\
\hline T2 & Participants communicate openly with one another. \\
\hline M1 & Participants share an overarching mission. \\
\hline M2 & $\begin{array}{l}\text { What we are trying to accomplish as a program would be difficult for a single } \\
\text { organization to accomplish on their own. }\end{array}$ \\
\hline $\mathrm{CP} 1$ & $\begin{array}{l}\text { This program has the ability to survive anything even if it had to make some major } \\
\text { changes to reach its goals. }\end{array}$ \\
\hline CP2 & Program participants are dedicated to making this program a success. \\
\hline KF1 & Participants are open to discussing different options or ways of working. \\
\hline KF2 & $\begin{array}{l}\text { Informal conversations between program participants should happen on a regular } \\
\text { basis. }\end{array}$ \\
\hline $\begin{array}{l}\text { Global } \\
(\mathrm{r})\end{array}$ & $\begin{array}{l}\text { I would expect the relationships among program participants to be relatively } \\
\text { impersonal. }\end{array}$ \\
\hline \multicolumn{2}{|r|}{ Systemic Dimension (Formality) } \\
\hline IMF1 & $\begin{array}{l}\text { Participating organizations should regularly participate in brainstorming sessions } \\
\text { to discuss improvements to the program. }\end{array}$ \\
\hline $\begin{array}{l}\text { IMF2 } \\
(\mathrm{r})\end{array}$ & $\begin{array}{l}\text { Most of the communications between program participants is through non-verbal } \\
\text { means. }\end{array}$ \\
\hline A1 & There is a clear process for making decisions. \\
\hline A2 & Participants must relinquish much of their control and authorit \\
\hline $\mathrm{RC} 1$ & Participants in this program have clearly defined roles and responsibilities. \\
\hline $\mathrm{RC} 2$ & $\begin{array}{l}\text { Program staff tend to act in a distinct and recognizable way (evidence use of words } \\
\text { acronyms people outside the program may not understand) }\end{array}$ \\
\hline Global & $\begin{array}{l}\text { The participating organizations hold collective ownership of various assets (i.e. } \\
\text { database or electronics) }\end{array}$ \\
\hline
\end{tabular}

\section{Measurements of Study Constructs at the Managerial Level}

Drawing from the VIEW caseworker survey, as reported in table 6, the grant coordinator survey included several similar statements for each dimension, but the wording was altered to better capture the expectations of participants at the managerial level. Given the limited number of cases (13), non-traditional methods to test the validity and reliability of the survey instrument and data were used. This included comparing the scores of these primary statements with a global survey statement, also reported in table 6, which represented a defining characteristic of either the relational or the systemic dimension of network functioning. Then, achieving triangulation of the data, the scores were compared with notes from the interviews with each grant coordinator and the text of each network's grant proposal. More specifically, this study examined the interview responses to two open-ended questions, which were designed to assess one of the dimensions, also reported in table 6.

To score each respondent, the weighting of each item was adjusted so that the items were treated equally. Then, the associated responses for each dimension were summed, and, for ease of presentation, the scores were transformed so that the assigned scores were out of 100. In all but one case, the interviews and grant proposal supported the scores produced by this survey. Only the scores for network 1 were much lower than the other materials would suggest. Given the reliability of the other scores, then, this study was confident moving forward with the survey scores as a representation of managerial expectations or the theory of action for each network. 
Figure 3. Process-Related Divergence at the Street-Level
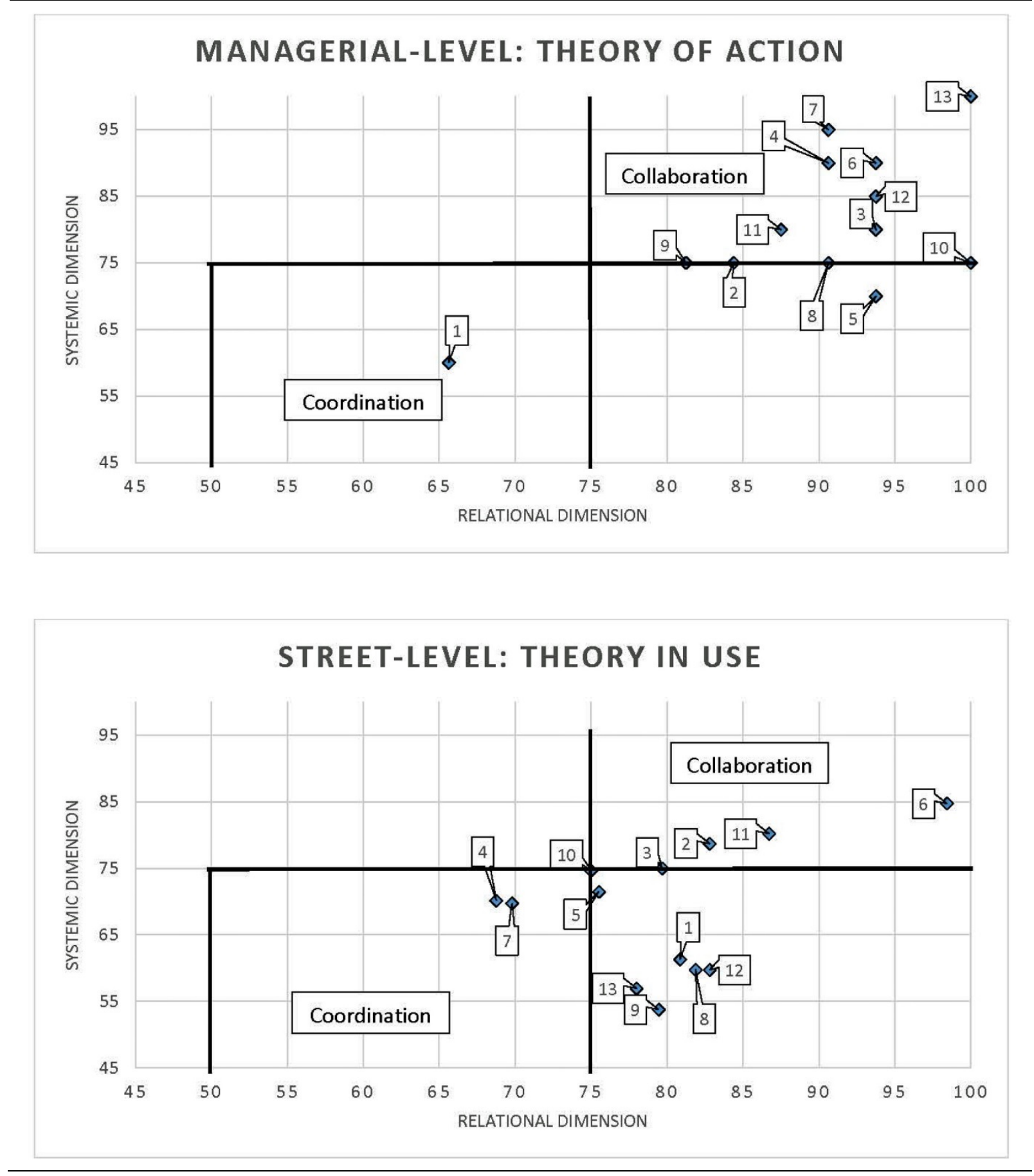

\section{Exploratory Analysis and Findings}

An analysis and comparison of the survey scores did show some evidence in support of the existence of process-related divergence at the street level of many of these networks. First, $44 \%$ of the VIEW caseworkers relational scores indicated a level of social capital that would not support the expectations of their grant coordinators. Additionally, $66 \%$ of their systemic scores 
indicated a level of formality that would not support the expectations of their grant coordinators. Second, averaging the VIEW caseworkers' scores to assign each network a relational and systemic score showed that only four of the 13 networks $(2,3,6$, and 11) showed the levels of social capital and formality necessary for it to function as expected. Figure 3 depicts this mismatch between the theory in use and the theory of action, otherwise referred to as process-related divergence at the street level, visually and reports the associated scores. As depicted, the majority of the networks are showing the level of social capital necessary for them to function as expected. However, they are not showing the level of formality that would be necessary for them to function as expected. Also, notice how the quadrants depict the differences in the strength or intensity of managerial expectations and the level at which that intensity is met at the street level. At the street level, networks 2, 6, and 11 come close to matching the intensity of managerial expectations, whereas the remaining networks do not. Perhaps, the managerial-level participants need to do more to help formalize the linkages among participants at the street level. This finding raises an interesting question. Over time, would the lack of formality lead to an erosion of social capital or would the level of social capital produce a higher level of formalization?

A review of the VIEW caseworkers' scores raised another important question. To what extent did the VIEW caseworkers in each network share similar relational and systemic perspectives? To address this question, this study transformed the standard deviations of the relational and systemic scores for each network into ordinal measures of convergence. These measures depict how closely the scores cluster around their arithmetic mean and represent four levels of convergence: strong, moderate, weak, and very weak (Meier \& Brudney, 2002; Pearson, 2010). ${ }^{2}$ As depicted in table 7, none of the networks showed at least a moderate convergence on both measures. ${ }^{3}$ This finding suggests that the VIEW caseworkers in each network were approaching their participation in the endeavor in a quite dissimilar way.

Last, these findings led to one more question of interest. Were the networks that showed littleto-no process-related divergence at the street level doing anything differently than the other networks? While the grant proposals were rather vague in regards to how each network was expected to function, networks 6 and 11 did include the most detail. Also, the grant coordinator for network 6 described two monthly meetings, the second of which specifically addressed the issue of participating in a network. The first meeting addressed policy concerns and provided participants with an opportunity to discuss their cases. The second meeting served as a training session where the network participants engaged in team-building exercises and an open dialogue or forum, where they discussed the ins and outs of working together and how their programs was supposed to function (Grant Coordinator 1, personal communication, February 8, 2011). Many of the other grant coordinators described monthly meetings, but the focus appeared to be the breakdown of cases and not the network relationship. As described by the grant coordinator, network 11 developed an extensive program orientation for new hires, which focused explicitly on working in a multi-organizational setting. This program has new hires read the grant proposal and meet with their supervisors for a one-on-one discussion of how the program is expected to function. Then, to help them build interpersonal relationships with other participants, the new hires meet with each of the network's partners, so that they can develop a personal contact with each at the outset (Grant Coordinator 11, personal communication, February 10, 2011). No other grant coordinator described such an extensive on-boarding or orientation program. Interestingly, all of the participants in network 2 are housed in one

\footnotetext{
2 The ordinal levels of convergence are as follows: Strong the $\sigma$ is $\leq 5 \%$ of the mean; Moderate the $\sigma$ ranges between $6 \%-10 \%$ of the mean; Weak the $\sigma$ ranges between $11 \%-15 \%$ of the mean; and Very Weak the $\sigma$ is $\geq 16 \%$ of the mean.

${ }^{3}$ Network 12 only has one VIEW caseworker and is not included in this part of the analysis.
} 
Street-Level Divergence in the Functioning of Social Welfare Networks

building, and the grant coordinator stated that this gives them the opportunity to be in constant communication (Grant Coordinator 2, personal communication, February 8, 2011). The data did not suggest anything different about network 3.

\section{Discussion of Findings and Their Implications}

Having demonstrated the potential for process-related divergence at the street level of the network approach to governance, the above findings support the notion that network participation itself may trigger a sense-making challenge for the street-level participants. Perhaps, reflecting on their experiences and the many other things that might influence this sense-making process, the VIEW caseworkers developed their own understanding of how they were supposed to link up with the other network participants, both relationally and systemically. This, then, can be understood as the theory in use by participants at the street level. It appears that more is needed to be done to ensure that the network participants, both at the managerial and street levels, developed a collective or shared understanding of how their networks should function. Complicating such efforts, however, is the reality that many of the VIEW caseworkers navigating much of the same space also arrived at different perspectives and were approaching their participation in the endeavor in a dissimilar way.

Prior to this study, the participants at the managerial levels of many of these networks had given little to no attention to articulating a shared theory of action. Yet, this study demonstrated that they did have some expectations as to how their networks should function. And, in most cases, those expectations were not being met. This supports the notion that agreements worked out during the principled engagement stage of the throughput processes do not always feed-forward to the street level. For example, the same level of trust or commitment and willingness to relinquish some autonomy in support of a shared theory of action that exists at the managerial level does not automatically exist at the street level. The potential differences in the knowledge and experiences of participants at the managerial and street levels, as well as their histories with other network participants, increase the likelihood for such process-related divergence. This makes efforts to achieve a shared understanding of network functioning all the more vital. Yet, to date, this important piece of the overall governance puzzle has not been given due consideration.

There appears to be at least two plausible explanations for this study's findings related to process-related divergence at the street level. On one hand, the expectations of the participants at the managerial level may not have met the realities or demands experienced by participants at the street level. On the other hand, this divergence could due to the lack of attention managerial actors were given to share their expectations with the street-level workers and appropriately equip them to fulfill those expectations. While the lack of in-network convergence by the VIEW caseworkers might suggest that they are adapting pragmatically to the challenges they are facing and support the first explanation, the limited articulation of a shared theory of action supports the second explanation.

As supported by the efforts of networks 6 and 11 described above, street-level participants may benefit from some guidance as to how they are supposed link up with the other network participants. This may decrease the likelihood of divergence and should include sharing the logic behind a theory of action, including how it relates to the overall objectives of a network. Mechanisms such as an extensive program orientation may help to ensure that managerial expectations actually feed-forward to the street levels and are more clearly understood. A shared understanding of network functioning, however, also may require mechanisms to generate some 
feedback and, similar to what is offered by this study, assess what is actually happening at the street level. Such analysis would give participants at the managerial level an opportunity to assess whether the levels of social capital and formality necessary for their network to function as expected actually exist at the street level. From here, they can revisit their expectations and either revise them or develop strategies that might generate the levels needed to realize their theory of action.

The potential for process-related divergence at the street level, as demonstrated by this study, is an important factor in the process side of the network effectiveness equation. The failure to account for this possibility can distort efforts to assess and improve the throughput processes of the network approach. As previously discussed, there is widespread evidence, as reported by Vangen and Huxham (2003, p. 6), that networks are "difficult to manage and [that] the likelihood of disappointing outputs and failures is high." While not explored here, could some of this difficulty and failure be blamed on process-related divergence at the street level? For example, if managerial participants expected the VIEW caseworkers to collectively draw upon the knowledge, expertise, and resources of other network participants to develop innovative solutions to client barriers to employment they would likely expect their network to function as collaboration. If, however, the conditions at the street level more closely align with cooperation, then the likelihood of disappointing outputs would seem to be quite high.

\section{Conclusions}

Due to the limitations of the traditional top-down approach to government, the network has indeed become the new shape of the public sector. Yet there is widespread evidence that networks are difficult to manage and that the likelihood of disappointing outputs or failure is high. This article has uncovered a potential factor that, if misunderstood and mismanaged by practitioners, could thwart their potential for realizing a collaborative advantage. The network is not an undifferentiated form or approach to governances. If certain variations in network functioning do serve some objectives better than other variations, the realization of those objectives might hinge on whether or not participants at the managerial and street levels share that understanding. At the very least, a mismatch in the expectations of managerial level participants and the actual functioning at the street levels would complicate efforts to evaluate and improve upon network effectiveness. Practitioners hoping to realize a collaborative advantage, then, could benefit from examining the degree of process-related divergence present at the street levels of their networks. Utilizing the approach of this study, this might force them to garner feedback from participants at the street level and revisit their expectations while developing strategies for achieving improved alignment. This might include investments in the growth of participant social capital (relational dimension) or efforts to establish the appropriate level of formality (systemic dimension), such that the throughput process functions as expected. It is this process that enables participants to function as a collective. Managerial- and streetlevel alignment will either increase the likelihood that the participants will achieve their objectives or better position them to recognize the potential limitations of their choices regarding network functioning.

To further explore this line of reasoning, future studies should examine the relationship between levels of street-level divergence in network functioning and network failure. Here, network failure should at least include outcomes or the achievement of policy goals and network sustainability. Given the relatively small study population, future studies should also replicate these efforts on a larger scale and look for ways to improve upon this study's constructs. 
Street-Level Divergence in the Functioning of Social Welfare Networks

\section{Disclosure Statement}

The author declares that there are no conflicts of interest that relate to the research, authorship, or publication of this article.

\section{References}

Agranoff, R., \&Lindsay, V. A. (1983). Intergovernmental management: Perspectives from human service problem solving at the local level. Public Administration Review, 43, 227237. doi: $10.2307 / 976331$

Agranoff, R., \& McGuire, M. (2001). Big questions in public network management research. J ournal of Public Administration Research and Theory, 11, 295-326. doi:10.1093/ oxfordjournals.jpart.a003504

Ansell, C., \&Gash, A. (2008). Collaborative governance in theory and practice. J ournal of Public Administration Research and Theory, 18, 543-571. doi:10.1093/jopart/mum032

Austin, J . E. (2000). Strategic collaboration between nonprofits and business. Nonprofit and Voluntary Sector Quarterly, 29(1), 69-97. doi:10.1177/089976400773746346

Bailey, D., \& Koney, K. M. (2000). Strategic alliances among health and human service organizations: From affiliations to consolidations. Thousand Oaks, CA: Sage Publications, Inc.

Bollen, K. (2014). Structural equations with latent variables. New York, NY: J ohn Wiley and Sons. doi: 10.1002/9781118619179

Bright, L. (2013). Where does public service motivation count the most in government work environments? A preliminary empirical investigation and hypotheses. Public Personnel Management, 42, 5-26. doi:10.1177/0091026013484575

Briggs, S. R., \& Cheek, J.M. (1986). The role of factor analysis in the development and evaluation of personality scales. J ournal of Personality, 54, 106-148. doi:10.1111/j.14676494.1986.tb00391.x

Chen, B. (2010). Atecedents or processes? Determinants of perceived effectiveness of interorganizational collaborations for public service delivery. International Public Management J ournal, 13, 381-407. doi:10.1080/10967494.2010.524836

Coleman, J . S. (1988). Social capital in the creation of human capital. American J ournal of Sociology, 94, S95-S120. doi:10.1086/228943

Considine, M., \&Lewis, J . M. (1999). Governance at ground level: The frontline bureaucrat in the age of markets and networks. Public Administration Review, 59, 467-480. doi:10.2307/3110295

Considine, M., \&Lewis, J . M. (2012). Networks and interactivity: Ten years of street-level governance in the United Kingdom, the Netherlands and Australia. Public Management Review, 14, 1-22. doi:10.1080/14719037.2011.589613

Diamantopoulos, A., \& Siguaw, J . A. (2006). Formative versus reflective indicators in organizational measure development: A comparison and empirical illustration. British J ournal of Management, 17, 263-282. doi:10.1111/j.1467-8551.2006.00500.x

Eliss, K., Davis, A., \& Rummery, K. (1999). Needs assessment, street-level bureaucracy and the new Community care. Social Policy and Administration, 33, 262-280. doi:10.1111/1467$\underline{9515.00150}$

Emerson, K., \&Nabatchi, T. (2015). Evaluating the productivity of collaborative governance regimes: A performance matrix. Public Performance and Management Review, 38, 717747. doi:10.1080/ 15309576.2015.1031016 
J ournal of Public and Nonprofit Affairs

Emerson, K., Nabatchi, T., \& Balogh, S. (2012). An integrative framework for collaborative governance. J ournal of Public Administraton Research and Theory, 22, 1-29. doi:10.1093/jopart/mur011

Gajda, R. (2004). Utilizing collaboration theory to evaluate strategic alliances. American J ournal of Evaluation, 25, 65-77. doi:10.1177/ 109821400402500105

Gofen, A. (2013). Mind the gap: Dimensions and influence of street-Level divergence. J ournal of Public Administration Research and Theory, 24, 473-493. doi:10.1093/jopart/mut037

Goldsmith, S., \& Eggers, W. (2004). Governing by network: The new shape of the public sector. Washington, DC: Brookings Institution Press.

Gould, L. J ., Ebers, R., \& Clinchy, R. M. (1999). The systems psychodynamics of a joint venture: Anxiety social defences and the management of mutual dependence. Human Relations, 52, 697-714. doi: $10.1177 / 001872679905200602$

Hair J r, J . F., Hult, G. T. M., Ringle, C., \&Sarstedt, M. (2016). A primer on partial least squares structural equation modleing (PLS-SEM). Los Angeles, CA: Sage Publications, Inc.

Harbert, A. S., Finnegan, D., \& Tyler, N. (1997). Collaboration: A study of a children's initative. Adminstration in Social Work, 21, 83-107. doi:10.1300/j147v21n03 05

Henseler, J ., Ringle, C. M., \& Sarstedt, M. (2015). A new criterion for assessing discriminant validity in variance-based structural equation modeling. J ournal of Academy of Marketing Science, 43, 115-135. doi:10.1007/s11747-014-0403-8

Hora, M. T., \& Millar, S. B. (2011). Education partnerships: Navigating diverse cultural contexts to turn challenge into promise. Sterling, VA: Stylus Publishing.

House, R. J ., \& Rizzo, J . R. (1972). Role conflict and ambiguity as critical variables in a model of organizational behavior. Organizational Behavior and Human Performance, 7, 467505. doi:10.1016/0030-5073(72)90030-x

J ewell, C. J ., \& Glasser, B. E. (2006). Toward a general analytic framework: Organizational settings, policy goals, and street-level behavior. Administration and Society, 38, 335364. doi:10.1177/0095399706288581

Keast, R., Mandell, M. P., Brown, K., \&Woolcock, G. (2004). Network structures: Working differently and changing expectations. Public Administration Review, 64, 363-371. doi:10.1111/j.1540-6210.2004.00380.x

Lipsky, M. (1980). Street-Level bureaucracy: Dilemmas of the individual in public services. New York, NY: Russell Sage Foundation.

Lynn, L. E., Heinrich, C. J ., \& Hill, C. J . (2001). Improving governance: A new logic for research. Washington, DC: Georgetown University Press.

Mandell, M., \& Steelman, T. (2003). Understanding what can be accomplished through interorganizational innovations: The importance of typologies, context, and management strategies. Public Management Review, 5, 197-224. doi:10.1080/1461667032000066417

Margerum, R. D. (2001). Organizational commitment to integrated and collaborative management: Matching strategies to constraints. Environmental Management, 28, 421431. doi:10.1007/s002670010234

Margerum, R. D. (2002). Collaborative planning building consensus and building a distinct model for practice. J ournal of Planning Education and Research, 21, 237-253. doi:10.1177/0739456x0202100302

Maroulis, S., \&Wilensky, U. (2014). Social and task interdependencies in the street-level implementation of innovation. J ournal of Public Administration Research and Theory, 25, 721-750. doi:10.1093/jopart/mut084

Mattessich, P., Murray-Close, M., \& Monsey, B. (2001). Collaboration: What makes it work. St Paul, MN: Fieldstone Alliance. 
Meek, J . W., De Ladurantey, J ., \&Newell, W. H. (2007). Complex systems: Governance and policy administration consequences. Emergence: Complexity and Organization, 9(1), 24-36.

Meier, K. J ., \& Brudney, J . L. (2002). Applied statistics for public administration. Boston, MA: Harcourt Press.

Oberfield, Z. W. (2010). Rule following and discretion at government's frontlines: Continuity and change during organization socialization. J ournal of Public Administration Research and Theory, 20, 735-755. doi:10.1093/jopart/mup025

Ostrom, E. (1990). Governing the commons: The evolution of institutions for collective action. Cambridge, England: Cambridge University Press.

Pearson, R. W. (2010). Statiscial persuasion: How to collect, analyze, and present data ... accurately, honestly, and persuasively. Los Angeles, CA: Sage Publications, Inc.

Porter, L. W., Steers, R. M., Mowday, R. T., \&Boulian, P. V. (1974). Organizational commitment, job satisfaction, and turnover among psychiatric technicians. J ournal of Applied Psychology, 59, 603-609. doi:10.1037/h0037335

Provan, K. G., \& Kenis, P. (2007). Modes of network governance: Structure, management, and effectiveness. J ournal of Public Administration Research and Theory, 18, 229-252. doi:10.1093/jopart/mum015

Rice, L. E., \& Mitchell, T. R. (1973). Structural determinants of individual behavior in organizations. Administrative Science Quarterly, 18, 56-70. doi:10.2307/2391927

Romzek, B., LeRoux, K., J ohnston, J ., Kempf, R. J ., \& Piatak, J . S. (2014). Informal accountability in multi-sector service delivery collaborations. J ournal of Public Administration Research and Theory, 24, 813-842. doi:10.1093/jopart/mut027

Taylor-Powell, E., Rossing, B. E., \& Geran, J. (1998). Evaluating collaboratives: Reaching the potential. Madison, WI: University of Wisconsin-Extension.

Thomson, A. M. (2001). Collaboration: Meaning and measurement (Unpublished doctoral dissertation). Indiana University, Bloomington, IN.

Thomson, A. M., \&Perry, J . L. (2006). Collaboration processes: Inside the black box. Public Administration Review, 66, 20-32. doi:10.1111/j.1540-6210.2006.00663.x

Thomson, A. M., Perry, J. L., \& Miller, T. K. (2009). Conceptualizing and measuring collaboration. J ournal of Public Administration Research and Theory, 19, 23-56. doi:10.1093/jopart/mum036

Turrini, A., Cristofoli, D., \&Frosini, F. N. (2010). Networking literature about determinants of network effectiveness. Public Administration, 88, 528-550. doi:10.1111/j.14679299.2009.01791.x

Vangen, S., \& Huxham, C. (2003). Nurturing collaborative relations: Building trust in interorganizational collaboration. J ournal of Applied Behavioral Science, 39, 5-31. doi:10.1177/0021886303039001001

Virginia Department of Social Services. (2011). Employment advancement for TANF participants. Retrieved from https:/ / www.dss.virginia.gov/ form/ grants/ ben-13045.html

Woodland, R. H., \&Hutton, M. S. (2012). Evaluating organizational collaborations: Suggested entry points and strategies. American J ournal of Evaluation, 33, 366-383. doi:10.1177/ 1098214012440028

\section{Author Biography}

J. Travis Bland is an assistant professor of public administration at the University of IllinoisSpringfield. His research interests include the network approach to governance, street-level 
J ournal of Public and Nonprofit Affairs

behavior, social welfare, and the normative and ethical foundations of our Constitutional Democratic Republic. 